\title{
Engaging the Reluctant? Service Learning, Interpersonal Contact, and Attitudes toward Homeless Individuals
}

Thomas Knecht, Westmont College

Lisa M. Martinez, University of Denver

ABSTRACT This article examines the extent to which service-learning courses affect students' attitudes and opinions. Elsewhere, we used a pre/postsurvey field experiment to demonstrate that volunteering with a homeless person tends to erode the stereotypes held by the domiciled-a confirmation of the venerable contact hypothesis. Here we use the same research design to assess whether students in service-learning courses exhibit a similar type of opinion change after spending a day with a homeless person. We find that even with limited contact a significant number of service-learning students came away from their time with homeless individuals holding fewer stereotypes and with a more nuanced perspective on the causes and consequences of homelessness. Nevertheless, working with a homeless person did have a negative effect on some students and contact generally failed to change students' views on public policy.

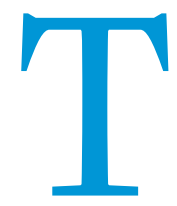

he well-documented benefits of civic engagement have contributed to the spread of service-learning courses across college campuses. Service-learning courses (also known as community-based learning or experiential learning) ask students to perform public-spirited work as an integral and integrated part of the course curriculum (for a review of this literature, see Eyler et al. 2001). Proponents claim service-learning courses offer a number of benefits, not least of which is the development of students' civic skills (Astin and Sax 1998; Astin et al. 200o; Ehrlich 1999; Metz and Youniss 2003; Yates and Youniss 1998; for an opposite view, see Hunter and Brisbin 200o). Critics, however, counter that service-learning courses are akin to "compulsory volunteering" in which students perform community service simply to fulfill a course requirement, gaining little out of the experience beyond a grade (Butin 2005; Fish 2003; Sobus 1995; Stukas et al. 1999).

This article examines the extent to which service-learning courses affect students' attitudes and opinions. Elsewhere, we used a pre/postsurvey field experiment to demonstrate that volunteering with a homeless person tends to erode the stereotypes held by the domiciled-a confirmation of the venerable contact hypothesis (Knecht and Martinez 2009). Here we use the same research design to assess whether students in service-learning courses

Thomas Knecht is an associate professor of political science at Westmont College. He can be reached at tknecht@westmont.edu.

Lisa M. Martinez is an associate professor in the department of sociology and criminology at the University of Denver. She can be reached at lisa.martinez@du.edu. exhibit a similar type of opinion change after spending a day with a homeless person. We find that, even with limited contact, a significant number of service-learning students came away from their time with homeless individuals holding fewer stereotypes and expressing a more nuanced perspective on the causes and consequences of homelessness. Nevertheless, working with a homeless person did have a negative effect on some students, and contact generally failed to change students' views on public policy. In sum, we find service learning to be something of a mixed bag: it helps create more compassionate students, but it does little to affect political attitudes.

\section{CIVIC ENGAGEMENT, SERVICE LEARNING, AND THE COLLECTIVE ACTION PROBLEM}

Service-learning courses are an intriguing option for instructors concerned with the state of civic engagement in America. Research has shown that service learning nurtures the political attitudes and civic skills essential in a healthy democracy, including greater political tolerance (Eyler and Giles Jr. 1999; Eyler et al. 1997; for an opposite view, see Niemi et al. 200o), reduced stereotyping (Astin and Sax 1998; Astin et al. 1999), greater social capital (Campbell 200o), and higher levels of internal and external efficacy (Eyler and Giles Jr. 1999; for an opposite view, see Kahne and Westheimer 2006). Moreover, proponents stress that service learning takes advantage of captive $(\mathrm{K}-12)$ or near-captive (higher education) audiences to ensure early exposure to community action, which can then breed a lifelong commitment to civic engagement 
(Metz and Youniss 2003; Youniss et al. 1997; see also Jennings and Stoker 2004).

Nevertheless, service-learning courses also impose costs on students. Most courses involve working with a community partner at an off-campus site, which requires that students spend time away from campus while still managing their academic, employment, and social calendars. Moreover, service-learning courses often expose college undergraduates to unfamiliar and uncomfortable environments, like homeless shelters. Students may then have to cope with cognitive costs that arise when their servicelearning experience confronts preconceived notions about political, economic, and social life. The result is a familiar dilemma: Service-learning courses can be good for student development and for the polity in general, yet the costs involved make it less likely that students will voluntarily take these courses.

In essence, then, service-learning courses face the same collective action problem as do other forms of civic engagement, which leave practitioners with three strategies to build enrollments. The first is to make service-learning courses optional. In this case, we should expect these courses would attract students who are already highly engaged and civic-minded. Although professors might desire a self-selected and motivated class roster, the downside is that service-learning courses end up preaching to the civically engaged choir instead of offering a transformative experience to erstwhile-disengaged students. A second strategy is to incentivize students to participate in service learning, either through extra credit assignments or as an alternative to traditional research papers. Again, the concern is that highly engaged students will opt in while the disengaged will opt out. The final strategy is to require that students take service-learning courses, either as part of their major or as part of the general education curriculum. The obvious benefit to the coercive approach is that it ensures that all students-the engaged and the disengaged-are given the opportunity for personal growth that often comes from community involvement. However, there are a number of potential downsides with the coercive approach, not least of which is the possibility that students come away from the course embittered from having been forced to volunteer.

Universities, departments, and instructors have many questions to answer before deciding on whether to offer servicelearning courses and, if so, how to structure the curriculum. One of those questions, and the one we focus on here, concerns individual-level attitudinal change or stability. Do those students who reluctantly enter a service-learning course leave with changed hearts and minds, ultimately grateful for the experience of working in the community? Alternatively, does forcing students into community service leave them feeling resentful, possibly walking away from the experience with more entrenched views than they came in with? Answers to these questions can help academics decide whether to make service-learning courses a requirement or an elective.

\section{METHODS}

This article uses Project Homeless Connect (PHC) as a field study to examine how interpersonal contact affects attitudes and opinions surrounding homelessness. PHC is a one-day event when volunteers escort homeless individuals to various booths providing health care, housing assistance, identification cards, job training, and legal services. The City of Denver has held several PHCs at the University of Denver (DU). ${ }^{1}$ As part of the event, DU fac- ulty were encouraged to integrate $\mathrm{PHC}$ into their course curriculum. We asked service-learning students and purposive volunteers (i.e., those volunteers not coerced or incentivized to participate in PHC) to take a pre- and a postsurvey bracketing their work at PHC; attitudinal change or stability was then assessed through paired-sample t-tests. All told, 79 service-learning students and 234 volunteers completed both the pre- and postsurvey.

An extended discussion of this methodology and its limits is found in Knecht and Martinez (2009), but here we briefly highlight a few considerations. The students in our study were from courses in a variety of disciplines, including political science, English, sociology, and theater arts. Many, but not all, of these service-learning courses focused on issues of homelessness and poverty. Moreover, all volunteers for Denver's PHC went through a one-hour training session that, although mainly covering the details of the event (i.e., where various booths were located, what time to show up), did feature some inspirational stories about the homeless and volunteers. As a result, we cannot fully separate whether attitudinal change from the pre- to postsurvey, if observed, was due to (a) contact with the homeless, (b) the nature of the course material and instruction, (c) PHC training, or (d) elements of all of the above. ${ }^{2}$

We initially intended to compare students who elected to take a service-learning course with those students who were required to take the course-a test of the hypothesis that forcing students to do community service affects what they get out of the experience. Unfortunately, our sample did not offer much ground for comparison: $72 \%$ of students were required to take the servicelearning course (a group we call required service learners) and relatively few-29\%-remarked that they elected to take the course because they were interested in the subject or liked the servicelearning component (a group we call self-selected service learners). Recognizing that we have a small sample size, we nevertheless checked whether there were attitudinal differences, pre- to postsurvey, between the required service learners and self-selected service learners by running simple crosstabs with chi-square as a measure of significance. In 28 questions (available from the authors but not reported here) that gauged participants' attitudes and level of empathy toward homeless individuals as well as their policy and spending preferences for combating homelessness, we found no case in which the attitudes of required service learners differed significantly from self-selected service learners. ${ }^{3}$ As a result, we will subsequently refer to all students collectively as service learners.

Our article is ultimately interested in whether working with homeless individuals changes the opinions of service learners. We use purposive volunteers for PHC as a baseline to compare the attitudinal change or stability of service learners. Again, purposive volunteers are those individuals who were neither overtly coerced nor incentivized to participate in PHC. ${ }^{4}$ Comparing service learners (who are largely required to work with the homeless) with purposive volunteers (who willingly worked with the homeless) allows us to examine whether voluntary participation is a necessary component of attitudinal change resulting from interpersonal contact. Unlike service learners-who were exclusively undergraduates, aged 18-24-the demographics of purposive volunteers ran the gamut, from undergraduates to DU faculty and staff to individuals from the community. Although differences in sample populations might normally raise some red flags, remember that we are interested in the question of whether attitudinal change is more pronounced in purposive volunteers 
than in service learners. Because we are interested in attitudinal change, not the nature of those attitudes (a point discussed in more depth later in the article), comparing dissimilar samples seems reasonable.

\section{RESULTS}

Tables 1 and 2, which present the bulk of our findings, require a bit of prior explanation. Table 1 provides the pre- and postsurvey means for each question, t-test scores, and standard indicators of statistical significance. Table 1 provides an aggregate view of attitudinal change or stability, but it does not capture the individuallevel dynamics that are of most interest. To provide a simple look at individual-level attitudinal change/stability, table 2 compares respondents' answers in the presurvey with their answers in the postsurvey. The column headings of table 2 (negative, no change, and positive) reflect the direction of opinion change. ${ }^{5}$ It is important to distinguish opinion change (shown in table 2) from the distribution of opinion (which we do not discuss). To illustrate opinion change, consider service learners' and volunteers' responses on a five-point Likert scale to the statement, "Homeless people are a danger to society." Table 2 shows that $40.5 \%$ of service learners and $39 \%$ of purposive volunteers felt the homeless were less of a danger to society after working at $\mathrm{PHC}-$ no real difference between the two groups. However, if we examine the distribution of opinion of the postsurvey (not reported), we find that $28 \%$ of service learners and $41 \%$ of purposive volunteers strongly disagreed that the homeless were a danger to society-a significant difference between the two groups. Because of the nature of our research question, and because ours is a nonrepresentative sample, we focus solely on opinion change/stability rather than the overall distribution of opinion.

Tables 1 and 2 show that working with homeless persons had a positive impact on the opinions of many service learners, with the effect most pronounced in the perceptions of the homeless and empathy categories. For example, table 1 shows that service learners went from feeling uneasy around the homeless (2.51 mean in the presurvey) to feeling less uneasy around the homeless (3.06 mean in the postsurvey). ${ }^{6}$ Table 2 offers another way to view this change. After PHC, $45.5 \%$ of service learners said they felt more comfortable around the homeless. Many of the openended responses also speak to breaking down the stigma of homelessness. One service learner wrote, "It [PHC] was an eye opening experience that changed my view of homeless people. I now understand that there is no structure that can be applied to all homeless people because they are so many and so different, coming from all ages and all walks of life." Another student commented, "Getting one-on-one experience with a homeless client served to break down many of the preconceptions that I had about homelessness. It was also good to know that there were people who were willing to help the homeless help themselves, rather than giving handouts or shunning them altogether."

How do the results of our service learners stack up against the purposive volunteers? On one hand, it appears that spending time with a homeless person had a less significant effect on service learners than it did on the purposive volunteers. For instance, while service learners experienced a statistically significant attitudinal change on eight out of the 31 questions in our analysis, purposive volunteers experienced significant opinion change in more than half the questions. Although the disparities in sample size can affect significance levels, one might draw the substantive conclusion that people who volunteer at civic events like PHC get more out of the experience than those who are required to be there.

On the other hand, a closer look at the data reveal that, in many ways, service learners actually experienced more attitudinal volatility than purposive volunteers. If we compare the "no change" columns of table 2, we see that service learners were more likely to change their perceptions of and empathy toward the homeless. Although most of this change was in a positive direction, service learners were also more likely to shift their opinions in a negative direction. For example, table 2 shows that, when asked whether the homeless were irresponsible, service-learners were more likely than purposive volunteers to shift their opinions in a negative direction (22.1\% to $17.5 \%)$ as well as a positive direction $(35.1 \%$ and 33.3\%). Again, some open-ended responses described negative experiences students had working with the homeless. As one student wrote, "I learned that some people take advantage of shelters and aid given to them. It was surprising to know that some homeless choose to be homeless."

Finally, our results show that although working at PHC changed perceptions of the homeless and increased empathy, contact did little to change opinions on public policy and governmental spending. Indeed, the attitudes of service learners were especially stable when it came to policy issues, such as whether the homeless have the right to sleep in public spaces or to panhandle. Moreover, working at PHC generally led both service learners and purposive volunteers to desire less governmental spending on homelessness. As we discussed in our earlier study (Knecht and Martinez 2009), the stability of policy preferences coupled with instability in perceptions of and empathy toward the homeless might reflect an internal conflict between beliefs and values. Therefore, even as more participants at PHC came to believe that homelessness was the result of structural inequalities instead of individual failings, those same respondents were still likely to retain their earlier values of economic individualism and self-reliance.

\section{CONCLUSION}

This article has found that service-learning courses can affect the attitudes and opinions of students in rather specific ways. A significant number of students who worked with Denver's homeless community came away from their relatively brief service-learning experience holding fewer stereotypes and with greater compassion toward the homeless. Nevertheless, interpersonal contact generally had a more significant affect on purposive volunteers than it did on service learners, and service learners were more likely to have a negative experience working with a homeless individual. Moreover, the erosion of the social stigma surrounding homelessness did little to affect how students viewed public policy and governmental spending.

Our goal of this article is to help teachers, departments, and/or universities think through whether to offer a service-learning curriculum and, if so, how to structure the program. Here, we are solely interested in whether service-learning courses affect students' attitudes toward the people and issues they studied. Of course, focusing on individual-level attitudinal change/stability is only small part in a much larger debate concerning service learning. Indeed, there are more fundamental questions to answer: Does service learning contribute to the mission of the university or department? Is there room in the general education or major 
Table 1

Pre- and Postsurvey Means for Service Learners and Purposive Volunteers

\begin{tabular}{|c|c|c|c|c|c|c|}
\hline & \multicolumn{3}{|c|}{ SERVICE LEARNERS } & \multicolumn{3}{|c|}{ PURPOSIVE VOLUNTEERS } \\
\hline & Pre-Test Mean & Post-Test Mean & $t$ & Pre-Test Mean & Post-Test Mean & $\mathrm{t}$ \\
\hline \multicolumn{7}{|l|}{ Perceptions of the Homeless } \\
\hline Danger to society & 3.68 & 4.01 & $3.04^{* *}$ & 3.89 & 4.22 & $4.20^{* * *}$ \\
\hline Irresponsible & 3.56 & 3.65 & 0.87 & 3.75 & 3.98 & $3.23^{* * *}$ \\
\hline Choose to be homeless & 4.13 & 4.08 & -0.45 & 4.12 & 4.33 & $2.86^{* *}$ \\
\hline Are lazy & 4.00 & 4.13 & 1.28 & 4.18 & 4.22 & 0.54 \\
\hline Victims or responsible ${ }^{1}$ & 3.54 & 3.68 & 0.94 & 3.65 & 3.78 & 1.84 \\
\hline Easily identifiable & 3.08 & 3.59 & $3.78^{* * *}$ & 3.38 & 3.9 & $6.51^{* * *}$ \\
\hline All walks of life ${ }^{2}$ & 4.36 & 4.62 & $2.33^{*}$ & 4.43 & 4.61 & $3.28^{* * *}$ \\
\hline Few children homeless & 4.41 & 4.58 & 1.47 & 4.52 & 4.7 & $2.95^{* *}$ \\
\hline Mentally ill & 3.13 & 3.34 & 1.51 & 3.12 & 3.35 & $3.26^{* * *}$ \\
\hline Substance abusers & 2.97 & 3.13 & 1.17 & 3.01 & 3.36 & $4.44^{* * *}$ \\
\hline \multicolumn{7}{|l|}{ Empathy } \\
\hline Unease around homeless & 2.51 & 3.06 & $4.25^{* * *}$ & 2.76 & 3.32 & $7.79 * * *$ \\
\hline Compassion for homeless & 3.67 & 3.98 & $3.30 * *$ & 4.05 & 4.40 & $3.56^{* * *}$ \\
\hline Homeless do with free time & 3.36 & 3.47 & 0.74 & 3.37 & 3.72 & $3.45^{* * *}$ \\
\hline How anyone becomes homeless & 4.06 & 4.09 & 0.24 & 4.24 & 4.36 & 1.31 \\
\hline Angry there are homeless in the US² & 3.91 & 4.13 & $2.46^{*}$ & 4.48 & 4.48 & .000 \\
\hline Willing to do volunteer work ${ }^{3}$ & 3.40 & 3.40 & 0.00 & 3.45 & 3.66 & $2.19 *$ \\
\hline Housing in your neighborhood ${ }^{3}$ & 2.92 & 3.02 & 1.09 & 3.05 & 3.28 & $2.35^{*}$ \\
\hline \multicolumn{7}{|l|}{ Policy } \\
\hline Coercive policies ${ }^{4}$ & 2.68 & 2.82 & 1.34 & 3.22 & 3.31 & 0.91 \\
\hline Preventative policies ${ }^{5}$ & 4.51 & 4.49 & -0.26 & 4.74 & 4.70 & -0.70 \\
\hline Sleep in public spaces ${ }^{6}$ & 1.85 & 1.85 & 0.00 & 1.85 & 1.83 & -0.94 \\
\hline Right to beg 6 & 1.74 & 1.77 & 0.57 & 1.71 & 1.55 & -1.59 \\
\hline Ruin parks ${ }^{7}$ & 1.49 & 1.59 & 1.67 & 2.15 & 2.17 & 0.32 \\
\hline Businesses lose customers ${ }^{7}$ & 1.46 & 1.40 & -1.00 & 1.96 & 2.01 & 0.60 \\
\hline Enough being done ${ }^{8}$ & 2.87 & 2.70 & $-2.43^{*}$ & 3.53 & 3.16 & $-2.80 * *$ \\
\hline \multicolumn{7}{|l|}{ Spending } \\
\hline Federal spending ${ }^{9}$ & 2.65 & 2.53 & -1.16 & 3.26 & 3.12 & $-3.15^{* *}$ \\
\hline State spending ${ }^{9}$ & 2.64 & 2.55 & -1.00 & 3.32 & 3.15 & $-3.20 * *$ \\
\hline City spending ${ }^{9}$ & 2.50 & 2.28 & $-2.26^{*}$ & 3.19 & 2.89 & $-5.27^{* * *}$ \\
\hline Pay extra $\$ 100$ taxes $^{3}$ & 2.87 & 2.96 & 0.96 & 2.98 & 3.14 & 1.76 \\
\hline Pay extra $\$ 500$ taxes $^{3}$ & 1.87 & 2.09 & $2.36^{*}$ & 2.10 & 2.19 & 1.04 \\
\hline Pay extra $\$ 1,000$ taxes $^{3}$ & 1.40 & 1.53 & 1.26 & 1.60 & 1.74 & 1.66 \\
\hline Programs for homeless cost too much & 3.35 & 3.35 & 0.00 & 3.84 & 4.02 & 1.65 \\
\hline
\end{tabular}

Notes. The means are calculated so that higher numbers indicate more favorable attitudes toward the homeless. Unless otherwise noted, the means are based on a five-point scale where 1 = strongly agree and 5 = strongly disagree.

${ }^{1}$ Five response categories where $1=$ responsible for their situation and $5=$ victims of circumstance.

${ }^{2}$ Five-point scale where $1=$ strongly disagree and $5=$ strongly agree.

${ }^{3}$ Four-point scale where $1=$ not willing at all and $4=$ very willing.

${ }^{4}$ Five-point scale where 1 = strongly support and $5=$ strongly oppose.

${ }^{5}$ Five-point scale where $1=$ strongly oppose and 5 = strongly support.

${ }^{6}$ Two response categories where $1=$ no and $2=$ yes.

${ }^{7}$ Two response categories where $1=$ yes and $2=$ no.

${ }^{8}$ Three response categories where $1=$ too much being done to help the homeless and $3=$ not enough being done to help the homeless.

${ }^{9}$ Three response categories where $1=$ too much and $3=$ not enough

${ }^{*} \mathrm{p}<.05,{ }^{* *} \mathrm{p}<.01,{ }^{* * *} \mathrm{p}<.001$ 
Table 2

Individual Level Change from Pre- to Postsurvey, Service Learners and General Volunteers

\begin{tabular}{|c|c|c|c|c|c|c|c|c|}
\hline & \multicolumn{4}{|c|}{ SERVICE LEARNERS } & \multicolumn{4}{|c|}{ GENERAL VOLUNTEERS } \\
\hline & Negative & No Change & Positive & $t$ & Negative & No Change & Positive & $\mathrm{t}$ \\
\hline \multicolumn{9}{|l|}{ Perceptions of the Homeless } \\
\hline Danger to society & 17.6 & 41.9 & 40.5 & $3.04 * *$ & 17.5 & 43.5 & 39.0 & $4.20^{* * *}$ \\
\hline Irresponsible & 22.1 & 42.9 & 35.1 & 0.87 & 17.5 & 49.1 & 33.3 & $3.23^{* * *}$ \\
\hline Choose to be homeless & 28.9 & 47.4 & 23.7 & -0.45 & 18.2 & 54.3 & 27.5 & $2.86^{* *}$ \\
\hline Are lazy & 21.1 & 50.0 & 28.9 & 1.28 & 20.5 & 57.9 & 21.6 & 0.54 \\
\hline Victims or responsible & 20.6 & 50.8 & 28.6 & 0.94 & 13.6 & 65.4 & 21.0 & 1.84 \\
\hline Easily identifiable & 18.4 & 35.5 & 46.1 & $3.78^{* * *}$ & 14.7 & 40.4 & 44.9 & $6.51^{* * *}$ \\
\hline All walks of life & 10.5 & 53.9 & 35.5 & $2.33^{*}$ & 11.3 & 64.7 & 24.0 & $3.28^{* * *}$ \\
\hline Few children homeless & 11.8 & 63.2 & 25.0 & 1.47 & 11.7 & 68.4 & 19.9 & $2.95^{* *}$ \\
\hline Mentally ill & 22.1 & 36.4 & 41.6 & 1.51 & 21.0 & 43.0 & 36.1 & $3.26^{* * *}$ \\
\hline Substance abusers & 20.8 & 45.5 & 33.8 & 1.17 & 16.8 & 42.3 & 40.9 & $4.44^{* * *}$ \\
\hline \multicolumn{9}{|l|}{ Empathy } \\
\hline Unease around homeless & 14.3 & 40.3 & 45.5 & $4.25^{* * *}$ & 11.3 & 44.9 & 43.8 & $7.79 * * *$ \\
\hline Compassion for homeless & 5.8 & 63.5 & 30.8 & $3.30 * *$ & 8.6 & 50.0 & 41.4 & $3.56^{* * *}$ \\
\hline Homeless do with free time & 22.6 & 41.5 & 35.8 & 0.74 & 10.3 & 62.1 & 27.6 & $3.45^{* * *}$ \\
\hline How anyone becomes homeless & 22.6 & 50.9 & 26.4 & 0.24 & 12.1 & 65.5 & 22.4 & 1.31 \\
\hline Angry there are homeless in the US & 11.3 & 56.6 & 32.1 & $2.46^{*}$ & 10.3 & 79.3 & 10.3 & .000 \\
\hline Willing to do volunteer work & 17.0 & 64.2 & 18.9 & 0.00 & 6.9 & 69.0 & 24.1 & $2.19 *$ \\
\hline Housing in your neighborhood & 13.2 & 66.0 & 20.8 & 1.09 & 13.8 & 53.4 & 32.8 & $2.35^{*}$ \\
\hline \multicolumn{9}{|l|}{ Policy } \\
\hline Coercive policies & 19.7 & 49.3 & 31.0 & 1.34 & 18.5 & 59.6 & 21.9 & 0.91 \\
\hline Preventative policies & 16.7 & 63.9 & 19.4 & -0.26 & 19.2 & 65.8 & 15.1 & -0.70 \\
\hline Sleep in public spaces & 2.4 & 95.1 & 2.4 & 0.00 & 6.0 & 90.2 & 3.8 & -0.94 \\
\hline Right to beg & 2.1 & 93.6 & 4.3 & 0.57 & 6.7 & 87.6 & 5.7 & -1.59 \\
\hline Ruin parks & 2.6 & 84.6 & 12.8 & 1.67 & 17.1 & 66.4 & 16.4 & 0.32 \\
\hline Businesses lose customers & 8.6 & 88.6 & 2.9 & -1.00 & 18.8 & 60.6 & 20.5 & 0.60 \\
\hline Enough being done & 18.5 & 77.8 & 3.7 & $-2.43^{*}$ & 23.4 & 68.0 & 8.6 & $-2.80^{* *}$ \\
\hline \multicolumn{9}{|l|}{ Spending } \\
\hline Federal spending & 17.6 & 73.5 & 8.8 & -1.16 & 21.3 & 66.4 & 12.2 & $-3.15^{* *}$ \\
\hline State spending & 18.2 & 72.7 & 9.1 & -1.00 & 23.8 & 62.1 & 14.2 & $-3.20 * *$ \\
\hline City spending & 30.6 & 61.1 & 8.3 & $-2.26^{*}$ & 28.5 & 59.9 & 11.6 & $-5.27 * * *$ \\
\hline Pay extra $\$ 100$ taxes & 15.1 & 60.4 & 24.5 & 0.96 & 12.1 & 58.6 & 29.3 & 1.76 \\
\hline Pay extra $\$ 500$ taxes & 9.4 & 58.5 & 32.1 & $2.36^{*}$ & 13.8 & 65.5 & 20.7 & 1.04 \\
\hline Pay extra $\$ 1,000$ taxes & 15.1 & 58.5 & 26.4 & 1.26 & 12.3 & 63.2 & 24.6 & 1.66 \\
\hline Programs for homeless cost too much & 11.8 & 76.5 & 11.8 & 0.00 & 8.8 & 56.1 & 35.1 & 1.65 \\
\hline
\end{tabular}

${ }^{*} \mathrm{p}<.05,{ }^{* *} \mathrm{p}<.01,{ }^{* * *} \mathrm{p}<.001$

requirements for service-learning courses? What is the philosophy of our service-learning curriculum? Do we want to send the best and most-engaged students out to serve the community (which suggests that a voluntary enrollment is the way to go)? Alternatively, do we want to offer a transformative learning environment to otherwise disengaged students (which suggests that requiring service-learning courses is the way to go)? Nevertheless, this article offers some insight to those wondering whether students get anything out of their service-learning experience if they are required to take the course.

On a personal level, we have seen the benefits of service learning in our courses. Students in our service-learning courses seem more engaged with the course material and generally benefit from the opportunity to put theory into practice. In addition, students are usually willing to put extra effort into the course because they know their work matters in the lives of real people. And we have personally witnessed the types of transformations described in this article. At the end of the term, many of our students express some variant of the statement: "I didn't want to work with [fill in the community group] when I first enrolled in your course, but I'm glad that I did." Nevertheless, instructors should be prepared for a variety of experiences that come from service learning. For example, as Foster-Fishman et al. (2010) note, strategies for improving service-learning outcomes include taking into account the processes and outcomes to be achieved as part of the project design as well as incorporating participants in the collection and analysis of relevant data about the population being studied. Likewise, Harkavy and Hartley $(2010,418)$ suggest that to positively 
engage students in the service-learning process, instructors, departments, and universities must connect the "core educational and civic mission" of the university to the project. Given that the University of Denver's mission is to serve the public good, there is room to consider ways of designing service-learning projects to reach both eager and reluctant students as well as the communities they serve.

Not all students will have great experiences in service-learning courses; not all students will learn the lessons we think they should; and not all students will come away appreciative for having been required to do community service. Service-learning pedagogy can be messy. However, we urge instructors to welcome the diversity of experiences that come from community-based learning and encourage students to voice opinions that might deviate from our own normative bent. The result, we have found, is measured in greater student engagement and personal development.

\section{NOTES}

1. The University of Denver is the oldest and the largest private university in the Rocky Mountain region. It serves approximately 10,00o students, both undergraduate and graduate. While reflecting some of the diversity of the broader society, it tends to enroll students from higher socioeconomic backgrounds.

2. We initially attempted to address this problem by having service learners take a presurvey on the first day of class, a second pre-survey the day before they were to volunteer with PHC, and a postsurvey immediately after their participation with PHC. This design would then allow us to capture how much attitudinal change, if any, was attributable to course content and how much change to actual contact with the homeless. Unfortunately, only five students completed the second postsurvey. Although we are unable to fully separate out effects, we did space surveys closely around PHC (the surveys were open two weeks before and two weeks after the event) to minimize threat of a spurious relationship.

3. Interestingly, the required service learners generally had a more positive experience at PHC than did the purposive volunteers, which suggests that students who might be the most reluctant to work in the community might end up getting the most out of the experience. While these results are suggestive, none reached conventional levels of statistical significance.

4. Of course, social coercion or solidary benefits are frequently used to increase civic participation, but are difficult to measure. Our sample of purposive volunteers includes those people who were not participating in PHC because of a service-learning course or required by their employer, fraternity or sorority, athletic team, etc.

5. We recognize that using the terms "negative" and "positive" carry a normative implication that not everyone will agree with. One might argue, for instance, that being less likely to say the homeless are substance abusers after volunteering does not reflect a "positive" attitudinal change at all. Rather, this collective opinion shift might indicate that respondents developed a distorted sense of the homeless after volunteering with PHC (i.e., volunteers became blind to the problem of substance abuse within the homeless community).

6. For all our measures, higher scores reflect more positive attitudes towards homeless individuals. Thus, for this measure, respondents were more likely to disagree with the statement, "I feel uneasy around homeless people" in the postsurvey than in the presurvey.

\section{REF E R E N C E S}

Astin, Alexander W., and Linda J. Sax. 1998. "How Undergraduates Are Affected by Service Participation." Journal of College Student Development 39 (3): 251-63

Astin, Alexander W., Linda J. Sax, and Juan Avalos. 1999. "Long-Term Effects of Volunteerism during the Undergraduate Years." Review of Higher Education 22 (2): 187-202.

Astin, Alexander W., Lori J. Vogelgesang, Elaine K. Ikeda, and Jennifer A. Yee. 200o. "How Service Learning Affects Students." Higher Education Research Institute.

Butin, Dan W. 2005. “'I Don't Buy It': Student Resistance, Social Justice, and Identity Construction." Inventio 7 (1).

Campbell, David E. 20oo. "Social Capital and Service Learning." PS: Political Science \& Politics 33 (3): 641-45.

Ehrlich, Thomas. 1999. "Civic Education: Lessons Learned." PS: Political Science $\mathcal{E}$ Politics 32 (2): 245-50.

Eyler, Janet, and Dwight E. Giles, Jr. 1999. Where's the Learning in Service-Learning? San Francisco: Jossey-Bass.

Eyler, Janet, Dwight E. Giles Jr., and John Braxton. 1997. "The Impact of ServiceLearning on College Students." Michigan Journal of Community Service Learning 4 (Fall): $5^{-15}$

Eyler, Janet S., Dwight E. Giles, Jr., Christine M. Stenson, and Charlene J. Gray. 2001. "At a Glance: What We Know About the Effects of Service-learning on College Students, Faculty, Institutions and Communities, 1993-2000." Nashville, TN: Vanderbilt University.

Fish, Stanley. 2003. "Aim Low." Chronicle of Higher Education 49 (36): $\mathrm{C}_{5}$.

Foster-Fishman, Pennie G., Kirsten M. Law, Lauren F. Lichty, and Christina Aoun. 2010. "Youth ReACT for Social Change: A Method for Youth Participatory Action Research." American Journal of Community Psychology 46 (1-2): 67-83

Harkavy, Ira, and Matthew Hartley. 2010. "Pursuing Franklin's Dream: Philosophical and Historical Roots of Service-Learning." American Journal of Community Psychology 46 (3-4): 418-27.

Hunter, Susan, and Richard A. Brisbin, Jr. 20oo. "The Impact of Service Learning on Democratic and Civic Values." PS: Political Science E Politics 33 (3): 623-26.

Jennings, M. Kent, and Laura Stoker. 2004. "Social Trust and Civic Engagement across Time and Generations." Acta Politica 39 (4): 342-79.

Kahne, Joseph, and Joel Westheimer. 2006. "The Limits of Political Efficacy: Educating Citizens for a Democratic Society." PS: Political Science and Politics 39 (2): 289-96.

Knecht, Thomas, and Lisa M. Martinez. 2009. "Humanizing the Homeless: Does Contact Change Attitudes?" Social Science Research 38 (3): 521-34.

Metz, Edward, and James Youniss. 2003. "A Demonstration that School-Based Required Service Does Not Deter-but Heightens-Volunteerism.” PS: Political Science and Politics 36 (2): 281-86.

Niemi, Richard G., Mary A. Hepburn, and Chris Chapman. 20oo. "Community Service by High School Students: A Cure for Civic Ills?" Political Behavior 22 (1): 45-69.

Sobus, Mark S. 1995. "Mandating Community Service: Psychological Implications of Requiring Prosocial Behavior.” Law \& Psychology Review 19 (Spring): 153-82.

Stukas, Arthur A., Mark Snyder, and E. Gil Clary. 1999. "The Effects of 'Mandatory Volunteerism' on Intentions to Volunteer." Psychological Science 10 (1): 59-64.

Yates, Miranda, and James Youniss. 1998. "Community Service and Political Identity Development in Adolescence." Journal of Social Issues 54 (3): 495-512.

Youniss, James, Jeffrey A. McLellan, and Miranda Yates. 1997. "What We Know about Engendering Civic Identity." American Behavioral Scientist 40 (5): 620-32. 